\title{
The Functional Role of Astrocyte Calcium Signaling in Cortical Blood Flow Regulation
}

\author{
Kyle R. Biesecker and $\oplus^{-A n j a}$ I. Srienc \\ Graduate Program in Neuroscience, University of Minnesota-Twin Cities, Minneapolis, Minnesota 55455 \\ Review of Bonder and McCarthy
}

Blood vessels in the CNS dilate in response to neuronal activity, thus supplying active neurons with adequate energy in a phenomenon called functional hyperemia. The cellular mechanism underlying functional hyperemia, known as neurovascular coupling, becomes dysfunctional in many disease states, such as hypertension, stroke, and Alzheimer's disease (Attwell et al., 2010). A prominent hypothesis holds that spillover of glutamate from active synapses binds to G-protein-coupled receptors (GPCRs) located on astrocytes. The resultant signaling cascades open $\mathrm{IP}_{3}$ type 2 receptors $\left(\mathrm{IP}_{3} \mathrm{R} 2\right)$, releasing calcium from internal stores into the cytosol. The increase in cytosolic calcium initiates the synthesis of vasoactive metabolites of arachidonic acid, which diffuse onto vascular smooth muscle cells to generate vascular dilations (Attwell et al., 2010).

In support of the role of glial calcium signaling in neurovascular coupling, data from ex vivo preparations suggest that stimulating neurons generates calcium in-

Received Oct. 24, 2014; revised Dec. 1, 2014; accepted Dec. 9, 2014.

K.R.B. is supported by NIH Predoctoral Training of Neuroscientists Grant T32GM0D8471, Neuroscience Vision Training Grant 5T32EY007133-20, MinnCResT Predoctoral Training Fellowship T90 DE 022732, and Fondation Leducq (08CVD02); A.I.S. is supported by an American Heart Association Predoctoral Fellowship (13PRE16960081) and Fondation Leducq (08CVD02). We extend many thanks to Eric Newman, Alfonso Araque, Joanna Kur, Tess Kornfield, and Michael Burian for helpful comments on the manuscript.

Correspondence should be addressed to Kyle R. Biesecker, 6-145 Jackson Hall, 321 Church St. SE, Minneapolis, MN 55455. E-mail: bies0051@umn.edu.

DOI:10.1523/JNEUROSCI.4422-14.2015

Copyright $\odot 2015$ the authors $\quad 0270-6474 / 15 / 350868-03 \$ 15.00 / 0$ creases in nearby glial cells, and artificially increasing calcium in the endfeet of glial cells can cause local changes in vascular diameter (Mulligan and MacVicar, 2004; Metea and Newman, 2006). More recently, in vivo mouse studies have demonstrated that sensory stimuli generate rapid calcium signals in astrocyte endfeet (Wang et al., 2006; Lind et al., 2013), while calcium uncaging in astrocytes also generates blood vessel dilations (Takano et al., 2006).

However, the above-mentioned studies have a number of technical weaknesses that make their findings difficult to interpret. First, classical calcium indicators, such as Oregon Green BAPTA and Fluo4AM, label neurons as well as glia (Lind et al., 2013; Nizar et al., 2013). Therefore, it is difficult to determine whether the observed calcium signals are truly glial in origin. Second, calcium uncaging may not generate a physiologically relevant signal, because it increases calcium to indeterminate levels and independently of GPCR signaling cascades. Finally, these studies report a wide range of glial calcium signaling latencies, some of which are too slow to mediate the functional hyperemia response, which has onset times of less than 1 s (Nizar et al., 2013). A precise measure of the latency of neuronally evoked glial calcium signals is needed to determine whether glial calcium signaling can mediate neurovascular coupling.

Recent work has challenged the theory of astrocyte calcium-dependent neurovascular coupling. Observations by Nizar et al. (2013) suggest that glial calcium sig- naling does not precede blood vessel dilations, and that signaling is sometimes absent. In a recently published article in The Journal of Neuroscience, Bonder and McCarthy (2014) extended these findings, demonstrating that Gq-GPCR-IP 3 R2dependent calcium signaling in cortical astrocytes is neither necessary nor sufficient to generate functional hyperemia responses in the visual cortex of in vivo lightly sedated mice.

To selectively image and manipulate astrocytes, Bonder and McCarthy (2014) injected adeno-associated viral vectors into the visual cortex of young adult mice. These viral vectors used a GFAP promoter to drive expression of various transgenes in cortical astrocytes. Specifically, hM3Dq DREADD (Designer Receptors Exclusively Activated by Designer Drugs) was expressed to permit selective pharmacological activation of the Gq pathways in astrocytes. Concurrently, the genetically encoded calcium indicators cyto-GCaMP3 (cytosolic), or Lck-GCaMP6 (membrane-bound) were expressed in astrocytes to image calcium signals with high sensitivity and without neuronal contamination. The authors imaged astrocytes of the visual cortex through a cranial window with two-photon microscopy while simultaneously monitoring rhodamine-dextran labeled blood vessels to measure blood flow changes.

The indisputable strength of this study is the variety of complementary genetic and imaging techniques that were used to probe whether glial calcium signaling can mediate functional hyperemia. The use of 
GCaMP in this study is a significant improvement over previous techniques, which relied on classical calcium indicators (Lind et al., 2013; Nizar et al., 2013). Using this improved calcium indicator technology, Bonder and McCarthy (2014) showed that stimulating the Gq-coupled DREADD receptor selectively expressed in glial cells reliably increased glial calcium signaling but failed to change blood flow. This novel finding directly contradicts demonstrations that uncaging calcium in glial cells results in the dilation of nearby blood vessels. In the corollary experiment, visual stimulation produced a robust blood flow increase without appreciable calcium elevations in glial perivascular endfeet of the visual cortex. These findings are strengthened by the observation that genetic elimination of the $\mathrm{IP}_{3} \mathrm{R} 2$ $\left(\mathrm{IP}_{3} \mathrm{R} 2 \mathrm{KO}\right)$ in mice did not disrupt the functional hyperemia response to visual stimulation, suggesting that glial calcium signaling does not mediate neurovascular coupling. These findings are in agreement with other published results reporting preserved functional hyperemia in $\mathrm{IP}_{3} \mathrm{R} 2$ $\mathrm{KO}$ animals in response to forepaw stimulation in the sensory cortex of anesthetized mice (Nizar et al., 2013).

Bonder and McCarthy (2014) also demonstrated that the animal's arousal state influences glial calcium dynamics because cortical astrocytes did not consistently respond to neuronal activity with calcium signals unless startle stimuli were used, a finding consistent with other recent reports (Paukert et al., 2014). Since anesthesia dramatically affects functional hyperemia (Franceschini et al., 2010) and glial calcium signaling (Thrane et al., 2012), using lightly anesthetized animals is an improvement toward understanding glial physiology and functional hyperemia.

Despite the advantages mentioned above, several weaknesses of Bonder and McCarthy's (2014) study limit the conclusions that can be drawn about the functional role of glial calcium signaling. First, the authors failed to assess both the transfection rates of their viral vectors and expression levels of the transgenes. Based on the imaging data displayed in their Figure 1, it appears that only a fraction of cortical astrocytes expressed the cyto-GCaMP3 or Lck-GCaMP6. Since GFAP is not widely expressed in the cortex (Nolte et al., 2001), using a GFAP promoter may drive expression in only a subpopulation of cortical astrocytes. Given the functional and genetic heterogeneity of astrocytes, it is plausible that a subpopulation of astro- cytes expressing little or no GCaMP could have generated calcium signals that were not observed by the authors; calcium signaling in these populations of untransfected astrocytes may play a pivotal role in neurovascular coupling.

Second, although Bonder and McCarthy's (2014) techniques allow for sensitive imaging of glial calcium signaling, it is conceivable that neuronally evoked calcium signals went undetected. Calcium signaling frequently occurs in the fine processes of glia, which are in close proximity to synapses where neurotransmitters are most likely to initiate calcium signals. However, this cellular subcompartment was not investigated by the authors. Additionally, although GCaMP is a highly sensitive calcium indicator, it is possible that weak or infrequent calcium signals could have gone undetected by the authors. One could argue that the validity of these critiques is undermined by Bonder and McCarthy's (2014) demonstration that $\mathrm{IP}_{3} \mathrm{R} 2$ $\mathrm{KO}$ animals have preserved functional hyperemia when calcium signaling is absent. But recent work has suggested that there are $\mathrm{IP}_{3} \mathrm{R} 2$-independent calcium signals that occur in fine astrocyte processes (Shigetomi et al., 2013; Haustein et al., 2014). Thus, calcium-dependent mechanisms, particularly those originating in the fine processes of astrocytes, cannot be ruled out as mediators of neurovascular coupling.

Third, while the genetic techniques Bonder and McCarthy (2014) used are powerful, altering an organism at the genetic level introduces confounds that can be difficult to control for. The $\mathrm{IP}_{3} \mathrm{R} 2 \mathrm{KO}$ animals used in this study are constitutive knock-outs, raising the possibility that, during development, these mice adapt to loss of $\mathrm{IP}_{3} \mathrm{R} 2$ by compensatory gene expression to retain functional hyperemia. Considering that Bonder and McCarthy's (2014) experiments were conducted under conditions of high oxygen, nitric oxidedependent mechanisms may dominate the functional hyperemia response (Attwell et al., 2010). Further, using DREADD receptors also has caveats. Given that the site of receptor expression on the cell can affect downstream outcomes, where are the DREADD receptors expressed on glial cells? Without proper alignment of the signaling machinery, one could speculate that blood flow responses could be absent even in the presence of DREADD-induced calcium signaling. Finally, it should be noted that the effects of GCaMP expression on calcium buffering or intracellular signaling have not been fully explored.
Bonder and McCarthy (2014) have provided strong evidence that a subpopulation of astrocytes in the visual cortex do not contribute to functional hyperemia via Gq-GPCR and $\mathrm{IP}_{3}$ R2-dependent calcium signaling using an impressive battery of genetic techniques. However, their study only captures calcium signaling in a fraction of cortical astrocytes, without considering the diversity of astrocytes within and between brain regions. The authors also do not investigate neuronally evoked calcium signaling in the fine processes of glial cells, the subcellular compartment ideally suited to detect neuronal activity. Finally, results from genetically manipulated organisms must be interpreted with care. These general shortcomings afflict the entire field of glial biology. It is critical that these weaknesses are addressed to compare glial function across brain regions and model systems, and to accurately understand the functional roles of glial calcium signaling. Nonetheless, Bonder and McCarthy's (2014) data convincingly challenges the current dogma that glial calcium signaling mediates neurovascular coupling.

\section{References}

Attwell D, Buchan AM, Charpak S, Lauritzen M, MacVicar BA, Newman EA (2010) Glial and neuronal control of brain blood flow. Nature 468:232-243. CrossRef Medline

Bonder DE, McCarthy KD (2014) Astrocytic GqGPCR-linked IP3R-dependent $\mathrm{Ca}^{2+}$ signaling does not mediate neurovascular coupling in mouse visual cortex in vivo. J Neurosci 34 : 13139-13150. CrossRef Medline

Franceschini MA, Radhakrishnan H, Thakur K, Wu W, Ruvinskaya S, Carp S, Boas DA (2010) The effect of different anesthetics on neurovascular coupling. Neuroimage 51: 1367-1377. CrossRef Medline

Haustein MD, Kracun S, Lu XH, Shih T, JacksonWeaver O, Tong X, Xu J, Yang XW, O’Dell TJ, Marvin JS, Ellisman MH, Bushong EA, Looger LL, Khakh BS (2014) Conditions and constraints for astrocyte calcium signaling in the hippocampal mossy fiber pathway. Neuron 82:413-429. CrossRef Medline

Lind BL, Brazhe AR, Jessen SB, Tan FC, Lauritzen MJ (2013) Rapid stimulus-evoked astrocyte $\mathrm{Ca}^{2+}$ elevations and hemodynamic responses in mouse somatosensory cortex in vivo. Proc Nat Acad Sci U S A 110:E4678-E4687. CrossRef Medline

Metea MR, Newman EA (2006) Glial cells dilate and constrict blood vessels: a mechanism of neurovascular coupling. J Neurosci 26:28622870. CrossRef Medline

Mulligan SJ, MacVicar BA (2004) Calcium transients in astrocyte endfeet cause cerebrovascular constrictions. Nature 431:195-199. CrossRef Medline

Nizar K, Uhlirova H, Tian P, Saisan PA, Cheng Q, Reznichenko L, Weldy KL, Steed TC, Sridhar VB, MacDonald CL, Cui J, Gratiy SL, Sakadzić 
S, Boas DA, Beka TI, Einevoll GT, Chen J, Masliah E, Dale AM, Silva GA, Devor A (2013) In vivo stimulus-induced vasodilation occurs without $\mathrm{IP}_{3}$ receptor activation and may precede astrocytic calcium increase. J Neurosci 33:8411-8422. CrossRef Medline Nolte C, Matyash M, Pivneva T, Schipke CG, Ohlemeyer C, Hanisch UK, Kirchhoff F, Kettenmann H (2001) GFAP promotercontrolled EGFP-expressing transgenic mice: a tool to visualize astrocytes and astrogliosis in living brain tissue. Glia 33:72-86. CrossRef Medline
Paukert M, Agarwal A, Cha J, Doze VA, Kang JU, Bergles DE (2014) Norepinephrine controls astroglial responsiveness to local circuit activity. Neuron 82:1263-1270. CrossRef Medline

Shigetomi E, Jackson-Weaver O, Huckstepp RT, O'Dell TJ, Khakh BS (2013) TRPAl channels are regulators of astrocyte basal calcium levels and long-term potentiation via constitutive D-serine release. J Neurosci 33:1014310153. CrossRef Medline

Takano T, Tian GF, Peng W, Lou N, Libionka W, Han X, Nedergaard M (2006) Astrocyte- mediated control of cerebral blood flow. Nat Neurosci 9:260-267. CrossRef Medline

Thrane AS, Rangroo Thrane V, Zeppenfeld D, Lou N, Xu Q, Nagelhus EA, Nedergaard M (2012) General anesthesia selectively disrupts astrocyte calcium signaling in the awake mouse cortex. Proc Natl Acad Sci U S A 109: 18974-18979. CrossRef Medline

Wang X, Lou N, Xu Q, Tian GF, Peng WG, Han X, Kang J, Takano T, Nedergaard M (2006) Astrocytic $\mathrm{Ca}^{2+}$ signaling evoked by sensory stimulation in vivo. Nat Neurosci 9:816-823. CrossRef Medline 